\title{
UTLIZAÇÃO DA APRENDIZAGEM ATIVA NO CURSO DE ENGENHARIA ELÉTRICA: PROTÓTIPO DE UM PROCESSO INDUSTRIAL DE TRANSPORTE, SELEÇÃO E ARMAZENAMENTO DE PEÇAS
}

DOI: 10.37702/2175-957X.COBENGE.2021.3705

Pedro Arthur Bessa Leao - peubessaleao@gmail.com

IFMG

Rua dos Viajantes 41

35570-132 - Formiga - MG

Willian Félix Souza e Silva - willianfelixx.ifmg@gmail.com

IFMG

Rua A 42

32900-000 - Igarapé - MG

Mariana Guimarães dos Santos - mariana.santos@ifmg.edu.br

IFMG Instituto Federal de Minas Gerais

Rua Tucuruca 570

35504-252 - Divinópolis - MG

Gustavo Lobato Campos - gustavo.lobato@ifmg.edu.br

IFMG Instituto Federal de Minas Gerais

Alameda das Latânias 1236

31270-800 - Belo Horizonte - MG

Resumo: São apresentados detalhes de um projeto interdisciplinar proposto pelas disciplinas laboratoriais de conversão de energia e de eletrônica II, ambas do sexto período do curso de Engenharia Elétrica do IFMG Campus Formiga. O objetivo foi o desenvolvimento de um projeto prático que permita a compreensão de conceitos associados às duas disciplinas. Neste caso, foi desenvolvido um protótipo de setor industrial composto por uma esteira transportadora e um guindaste. O sistema é responsável pela identificação, contagem, transporte e alocação adequada de um determinado material. Para o desenvolvimento do projeto foi necessária pesquisa bibliográfica referente à aplicação industrial das referidas disciplina. Destaca-se para a área de conversão itens como eletroímãs, relés e motores. Já para a 
disciplina de eletrônica cita-se a plataforma Arduino, responsável pela gestão e controle dos sensores e atuadores envolvidos no projeto. Como resultado são apresentadas etapas associadas ao desenvolvimento do projeto, assim como relato e discussão da experiência dos discentes e docentes envolvidos no mesmo. $O$ desenvolvimento deste permitiu o aprendizado e a associação de conhecimentos de motores elétricos, eletroímãs, sensores, Arduíno e programação. Assim,a execução do projeto permitiu o desenvolvimento de habilidades importantes para os "novos engenheiros", tais como: trabalho em equipe, capacidade de solucionar problemas, pragmatismo, cumprimento de prazos e metas e capacidade de redação de textos e roteiros técnicos fundamentais pra área de engenharia.

Palavras-chave: Aprendizagem ativa; Esteira transportadora; Guindaste; Arduíno. 


\section{COBENCE \\ 28 a 30 de SETEMBRO \\ UTLIZAÇÃO DA APRENDIZAGEM ATIVA NO CURSO DE ENGENHARIA ELÉTRICA: PROTÓTIPO DE UM PROCESSO INDUSTRIAL DE TRANSPORTE, SELEÇÃO E ARMAZENAMENTO DE PEÇAS}

\section{INTRODUÇÃO}

O ensino superior em todo mundo enfrenta o desafio de adaptação às novas exigências de formação profissional em função de mudanças sociais, econômicas, políticas, culturais e tecnológicas, vivenciadas nas últimas décadas. Estas novas exigências requerem também novas abordagens de ensino e aprendizagem (OLISKOVICS e DEL PAIVA). Neste contexto surgem metodologias baseadas nos conceitos de aprendizagem ativa e que utilizam a associação de conhecimentos multidisciplinares. Nestas, o aluno assume uma postura mais ativa, na qual a solução de problemas e o desenvolvimento de projetos cria oportunidades para a construção do conhecimento, destaca MASSETO (1998). Diversas estratégias têm sido utilizadas para promover a aprendizagem ativa como, por exemplo, a baseada na pesquisa e em projetos multidisciplinares.

Embasado em OLGUIN (2002), a interdisciplinaridade apoia-se na prática da interação entre os conteúdos do currículo de um curso. Permite o estabelecimento de conteúdos de diversas disciplinas.

Projetos interdisciplinares envolvem mais de uma disciplina nos procedimentos de estudos e execução. Estas atividades permitem a manifestação de aspectos envolvidos ou não no conteúdo do projeto (ZAINA e COVERSAN ,2005).

Este trabalho apresenta os resultados da aplicação de conceitos de interdisciplinaridade e de aprendizagem ativa no curso de graduação em engenharia elétrica do IFMG campus Formiga, nas disciplinas laboratoriais de conversão de energia e eletrônica. Foi proposto o desenvolvimento de um protótipo de sistema industrial para seleção e transporte de material. A escolha deste projeto se justifica pelo fato de que, atualmente, a maioria dos processos industriais são automatizados, visando a redução de custos de operação, a otimização do tempo gasto e o aumento da produtividade assim como da qualidade na entrega do produto final. Exemplos que corroboram esta afirmação podem ser vistos em indústrias para criação e montagem de peças de automóveis e outros meios de transporte, fábricas de jornais, indústrias alimentícias, indústria de calcinação e indústria têxtil e fábricas de cerveja (SANTOS; SANTOS; CASTRO, 2014)

São muitos, talvez imensuráveis, os setores industriais automatizados possíveis. Porém, é visto na maior parte deles, um predomínio de esteiras transportadoras e/ou braços (guindastes) robóticos na base constituinte destes processos. Se analisados, em especial, os guindastes, se pode notar o quão fundamental este se mostra na locomoção de materiais de grande porte, como de sucatas, contêineres e materiais de construção de altos edifícios. Um recurso bastante utilizado em transporte de materiais ferromagnéticos é o eletroímã, um núcleo ferromagnético envolto por espiras de um condutor, que ao ser energizado, se torna um ímã. Este recurso se mostra muito útil principalmente em ferros velhos.

Devido à importância destes equipamentos no setor industrial faz-se necessário que engenheiros ingressantes no mercado de trabalho possuam um conhecimento prévio a respeito da construção, manutenção e funcionamento destes. Assim, a proposta de construção de um de um protótipo, em escala reduzida, de transporte de um setor industrial, permitiu o conhecimento de dispositivos tais como: eletroímãs, sensores, atuadores, relés, motores, Arduíno e programação. 


\section{REVISÃO BIBLIOGRÁFICA}

Foram utilizados componentes cujo funcionamento baseia-se em circuitos eletrônicos e em circuitos magnéticos de conversão de energia. Estes são detalhados a seguir.

\section{Componentes Eletrônicos}

Os sensores são componentes eletrônicos que tem a capacidade de detectar/captar estímulos, seja por luz, umidade ou presença, e fornecer uma resposta a esse sinal (SILVEIRA, 2016). Neste trabalho, são utilizados sensores de obstáculos e sensor de distância ultrassônicos. Os sensores de distância ultrassônicos são compostos por um emissor e um receptor de ondas. O funcionamento é baseado na emissão de uma sonora de elevada frequência $(40 \mathrm{KHz})$. Ao emitir este sinal, um cronômetro de alta precisão é acionado que faz a contagem do tempo necessário para a onda encontrar o obstáculo e ser refletida no receptor (THOMSEN, 2011).

Tendo em vista que a velocidade do som é de conhecida, $340 \mathrm{~m} / \mathrm{s}$, é possível calcular a distância em que o sensor deve ser fixado para que a onda sonora atinja o obstáculo.

O sensor de obstáculo é composto por dois LEDs e um $\mathrm{Cl}$ comparador, sendo um LED emissor infravermelho e outro receptor. O seu funcionamento é de modo automático. Ao ser excitado com uma fonte de alimentação, este emite e recebe sinais de radiação infravermelha. No momento em que o sinal enviado encontra um obstáculo, o LED receptor compreende a existência do objeto e altera o nível lógico de alto para baixo. O display LCD (display de cristal líquido) é um componente gráfico utilizado como interfaces. Este dispositivo é formado por uma fina camada de cristal líquido envolvido por placas de vidro, com uma fonte de luz aplicada abaixo desta estrutura. A exibição das imagens ocorre devido ao líquido de cristal se tornar opaco ao ser energizado, impedindo assim, a passagem de luz (BOYLESTAD, 2013, p. 694).

Os displays LCD são caracterizados com base na sua capacidade gráfica, ou seja, de acordo com a quantidade de linhas e o número de caracteres por linha (BOYLESTAD, 2013, p. 694). A conexão do display LCD é realizada por meio de um microcontrolador. Este dispositivo eletrônico possui 16 entradas, sendo eles, alimentação, aterramento e sinal.

O microcontrolador utilizado foi o Arduino, que é uma plataforma de programação de fonte aberta, baseada em uma placa que possui linguagem de processamento $\mathrm{C} / \mathrm{C}++$ (BANZI, 2012).

Esta plataforma de desenvolvimento consiste em microcontroladores que podem ser empregados em projetos de diversas áreas. Microcontrolador é conceituado a partir da inserção de um microprocessador, temporizados e sistemas de comunicação em um circuito integrado. Como exemplo de uma plataforma microcontrolada, destaca-se o Arduino (FONSECA e VEJA, 2011; ADUINO, 2012).

A plataforma Arduino é composta por um hardware e software, no qual os sistemas digitais conectados aos atuadores e sensores tem a capacidade de aferir propriedades do ambiente e executar decisões lógicas.

O microcontrolador utilizado na plataforma Arduino Mega é o ATmega 1280, possui 54 pinos de entrada/saída, 16 entradas analógicas, frequência de $16 \mathrm{MHz}$, entre outros detalhes (ARDUINO, 2012).

\section{Componentes Magnéticos}


Os eletroímãs são equipamentos constituídos por um núcleo ferromagnético envolvido por uma bobina. Quando aplicado uma diferença de potencial, uma corrente elétrica circula pelas espiras do solenoide, criando-se campo magnético. Este campo magnético orienta os átomos do núcleo de ferro e faz com que ele se comporte como um imã, enquanto estiver energizado (CHAPMAN, 2012, p. 09).

Os motores de corrente contínua são equipamentos alimentados por fontes de tensão contínua, responsáveis pela conversão da energia elétrica em mecânica que é disponibilizada no eixo para movimentação de cargas. São utilizados neste trabalho, motores de passo e servo para o movimento do braço mecânico e da esteira.

Segundo (CHAPMAN, 2012, p.602), os motores de passo são equipamentos comumente aplicados em sistemas de controle e medição, projetados para, a cada pulso elétrico, rotacionarem uma angulação pré-determinada. Quanto às características, ressaltam-se (AGNIHOTRI, 2011): ausência de escovas, independência de cargas, posicionamento em malha aberta e torque estacionário.

Servo motores são equipamentos destinados para o controle de movimento que necessitam de posicionamento efetivo, rápida reposta e alto desempenho. Os servos possuem encoder e um controlador acoplados. Sendo assim, funcionam como atuador rotativo que assegura o controle, velocidade e posicionamento em malha fechada (MATOS, 2012).

Segundo Livia Cunha (2009), relés são dispositivos eletromecânicos que trabalham a partir da excitação elétrica de seus componentes internos, designados a fornecer modificações repentinas em circuitos elétricos, quando atingem as condições de entrada que coordena o dispositivo (SILVA, 2012). São utilizados para estabelecer o fluxo de correntes, operando no controle de circuitos, possibilitando a ligação, desligamento ou alterações temporárias no sistema (OLIVEIRA, 2010).

\section{METODOLOGIA}

Para que o projeto final fosse apresentado, em primeiro lugar foi elaborado um cronograma para montagem do projeto, definindo-se os prazos para entrega de cada etapa. Esta definição foi fundamental para que o projeto fosse entregue na data estipulada. Vale destacar que os assuntos das disciplinas de Eletrônica II e Conversão de Energia Elétrica destacados na seção de Revisão Bibliográfica, estarão diretamente relacionados em todas as etapas do projeto. A Tabela 1 apresenta o cronograma proposto para desenvolvimento do protótipo.

Tabela 1 - Cronograma de atividades

\begin{tabular}{|c|c|c|c|c|c|c|c|c|}
\hline Etapas em desenvolvimento / Semana & 1 & 2 & 32 & 45 & 6 & 7 & 8 & 9 \\
\hline Definição do tema & $\mathrm{X}$ & & & & & & & \\
\hline Pesquisas bibliográficas & $\mathrm{x}$ & $\mathrm{x}$ & $x$ & & & & & \\
\hline Programação da esteira & & & $x$ & $x$ & & & & \\
\hline Compra dos materiais da esteira & & & & $\mathrm{x}$ & & & & \\
\hline Programação do braço & & & & & $\mathrm{X}$ & & & \\
\hline Compra dos materiais do braço & & & & & & $\mathrm{x}$ & & \\
\hline Montagem da esteira & & & & & & & $\underline{X}$ & \\
\hline Montagem do braço & & & & & & & $\mathrm{X}$ & \\
\hline Testes & & & & & & & $\mathrm{x}$ & \\
\hline Ajustes finais & & & & & & & & \\
\hline
\end{tabular}


O sistema realiza a identificação do material ( $A$ ou $B$ ), em seguida o mesmo é colocado na esteira e um guindaste com eletroímã separa e direciona o material para 0 local desejado.

A ferramenta utilizada para interligar todo o sistema foi a plataforma Arduíno, para a qual foi desenvolvido um algoritmo que funcionava do seguinte modo: ao receber um sinal de um dos dois sensores ultrassônicos, o material é identificado, contado e, a partir disso, o motor de passo, que movimenta a esteira, é acionado para transporte do material. Um sensor de obstáculo infravermelho, localizado no final da esteira, identifica que o material está na posição desejada e, então, o motor servo do topo do guindaste e o eletroímã são acionados, levando o material ao destino desejado. O Arduíno é responsável pelo controle e junção de todas as partes do sistema e sua programação foi realizada em $\mathrm{C}_{++}$(com algumas modificações).

A Figura 1 representa o esquema de ligação para o pleno funcionamento eletrônico do protótipo, enquanto o fluxograma apresentado na Figura 2 ilustra o funcionamento deste.

Figura 1. Esquema de ligação dos componentes eletrônicos.

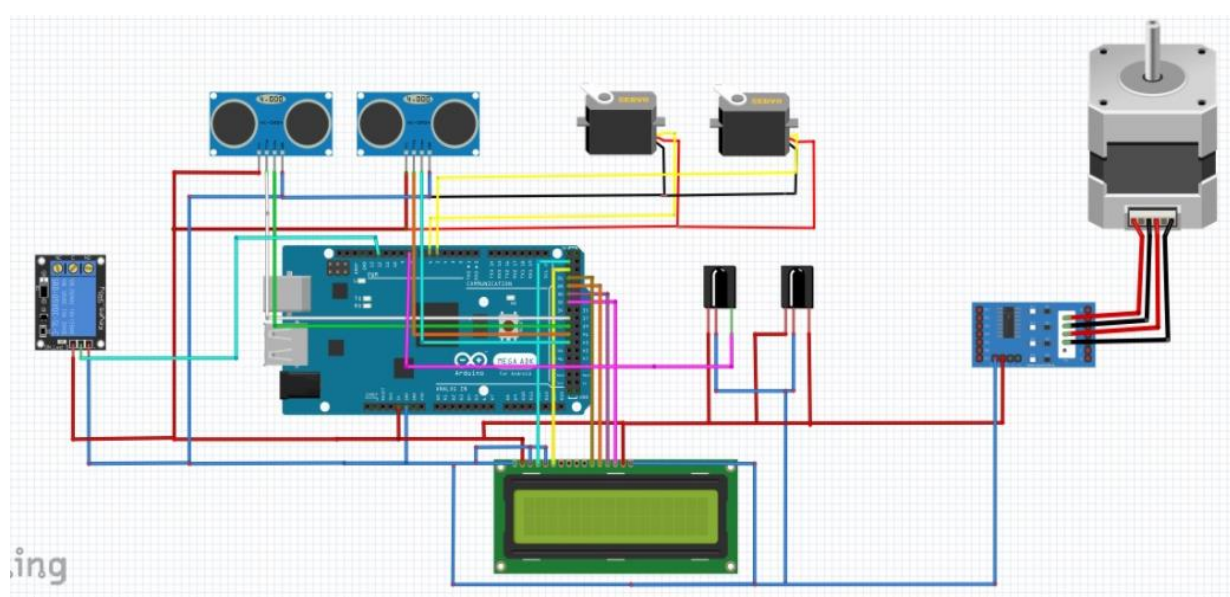

Fonte: Próprio Autor.

Figura 2. Funcionamento do Protótipo.

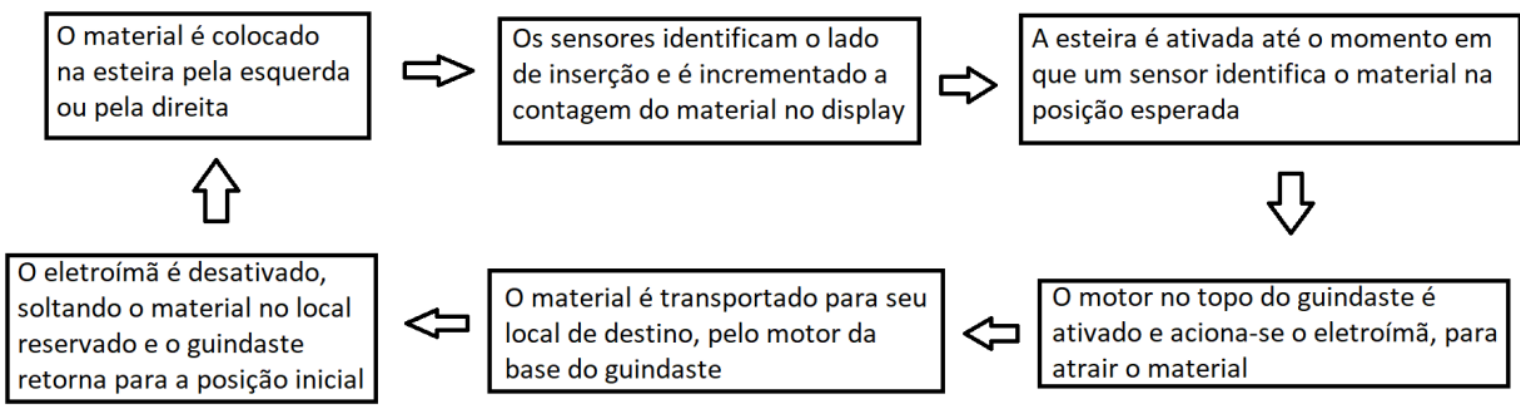

Fonte: Próprio Autor.

Pela Figura 1, pode-se identificar o Arduíno responsável por controlar o protótipo, o relé ao lado esquerdo do Arduíno, os dois servos motores, o motor de passo utilizados os 
sensores ultrassônicos e infravermelho além do display posicionado abaixo do microcontrolador.

A construção física do sistema, esteira e braço mecânico, foi feita em MDF e todos os componentes foram alocados nesta estrutura. Na parte frontal, foi fixado o display de LCD que exibe a contagem do material. $\mathrm{Na}$ parte posterior da placa frontal, são posicionados os dois sensores ultrassônicos, um de cada lado, a fim de perceber por qual dos lados está sendo inserido o material na esteira. No lado interno da esteira, é alocado o motor de passo, cuja função é movimentar a correia transportadora, por meio dos eixos e na parte interna, o sensor de obstáculo infravermelho, responsável por perceber o momento em que o material está na posição correta para ser pego pelo eletroímã.

O guindaste foi confeccionado com canos PVC de $25 \mathrm{~mm}$ e em sua base, é posicionado um motor servo MG995 TowerPro, responsável por manter firme a estrutura do guindaste e relacioná-lo, de acordo com o material transportado pela esteira. No topo do guindaste, foi acoplado um motor servo $9 \mathrm{~g}$ SG90, que possui a função de sustentação do eletroímã e direcionamento do braço conforme a programação do Arduino.

Para construir o eletroímã, foi utilizado um prego $18 \mathrm{JP} \times 27 \mathrm{LP}$, no qual foram enroladas 210 espiras de fio de cobre esmaltado. Para sustentação, foi colado a um pedaço de cano, do seu tamanho, e preso ao motor servo do topo. Foi acoplado também, em sua cabeça, uma fita, para diminuir o contato com o material. Sua energização se deu pelo lado de baixa tensão de um transformador 127/12V-1A, acionado por um módulo relé, este comandado pelo microcontrolador.

\section{RESULTADOS}

Para que o Arduino execute todas as ações propostas no escopo do projeto foi desenvolvido um algoritmo cuja lógica do código é apresentada na Figura 3.

Figura 3. Fluxograma Lógico do Protótipo

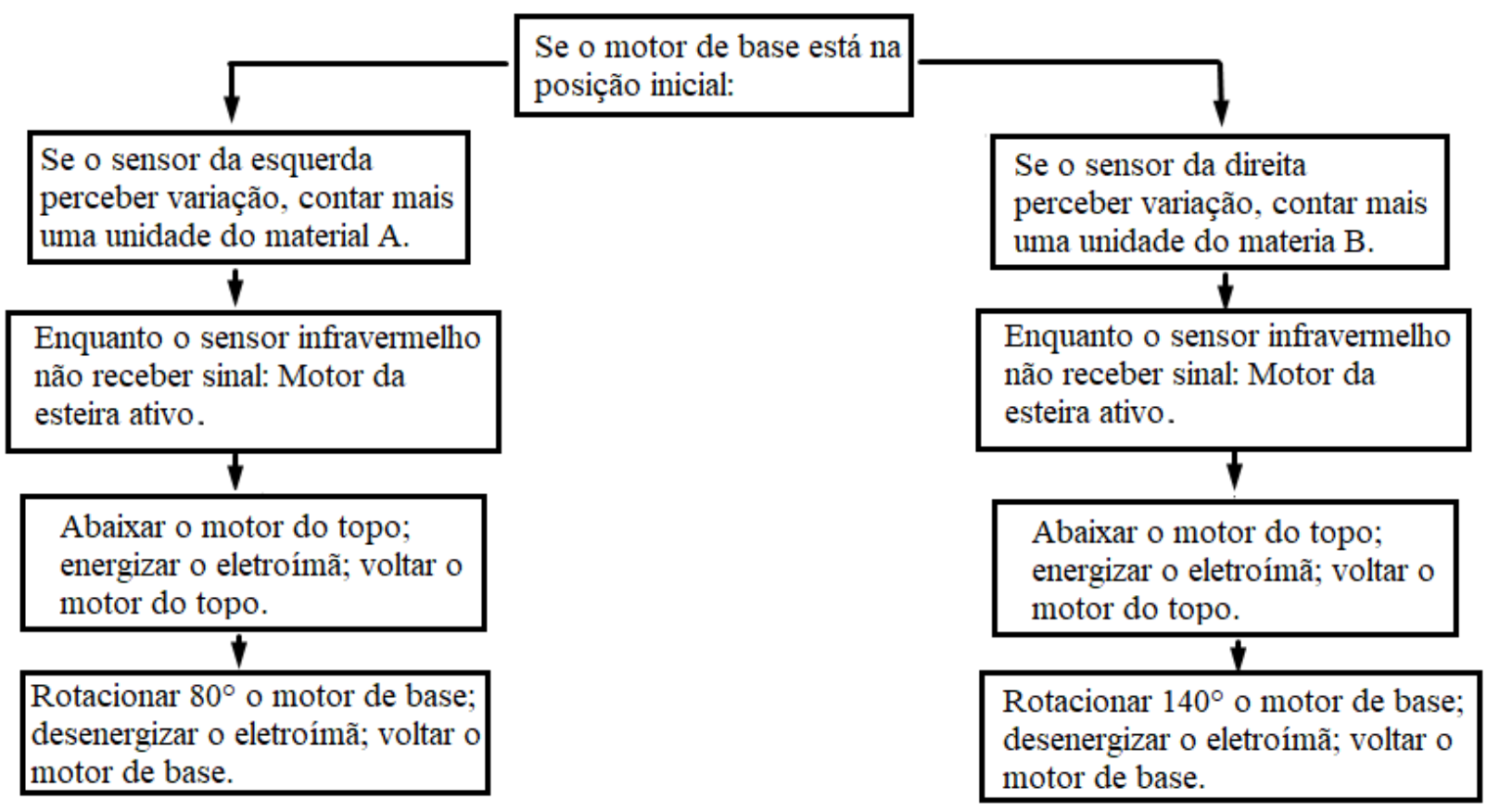

Fonte: Próprio Autor. 
Pelo fluxograma apresentado na Figura 3, pode-se perceber que quando o motor estiver na posição inicial os sensores poderão perceber variação e ativar os motores da esteira. Quando o sensor infravermelho, posicionado no final da esteira, perceber variação o motor da esteira será desativado e será acionado o guindaste. De acordo com o sensor que perceber variação, o material será separado pelo guindaste, girando $80^{\circ}$ ou $140^{\circ}$. A interdisciplinaridade é evidenciada pela Figura 3, pois os conceitos das disciplinas de Eletrônica II e conversão de energia estão diretamente relacionadas. O Arduino associa os dispositivos eletrônicos como os sensores aos dispositivos referentes a disciplina de conversão de energia, como energizar ou desenergizar o eletroímã.

O Protótipo foi desenvolvido de acordo com os procedimentos citados na seção de metodologia e sua montagem final pode ser visualizada na Figura 4.

Figura 4. Protótipo Final.

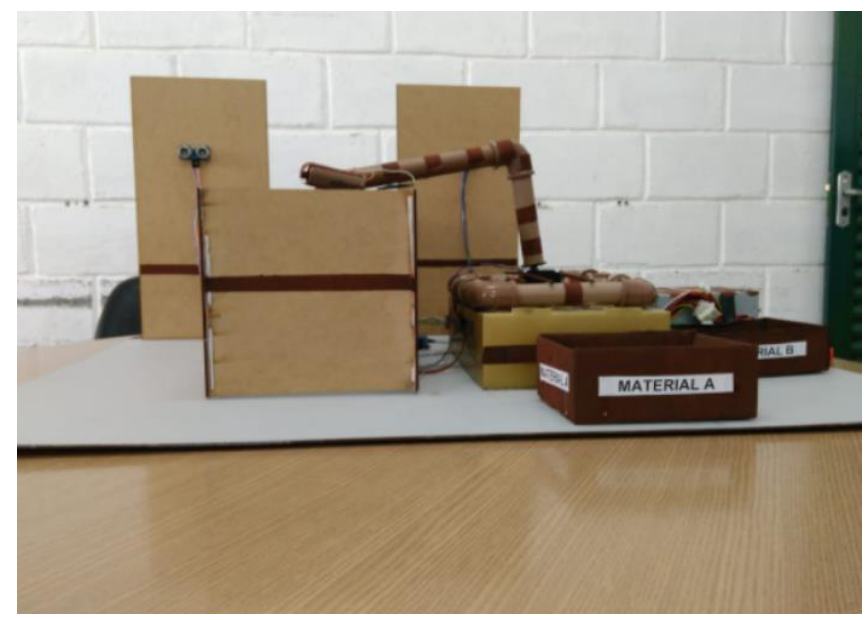

Fonte: Próprio Autor.

A Figura 5 representa a localização do sensor ultrassônico direito, não sendo exibido o sensor do lado esquerdo da esteira. Também foi destacado o sensor infravermelho, e o motor de passo que movimenta a esteira.

Figura 5. Localização de sensores e motor de Passo.

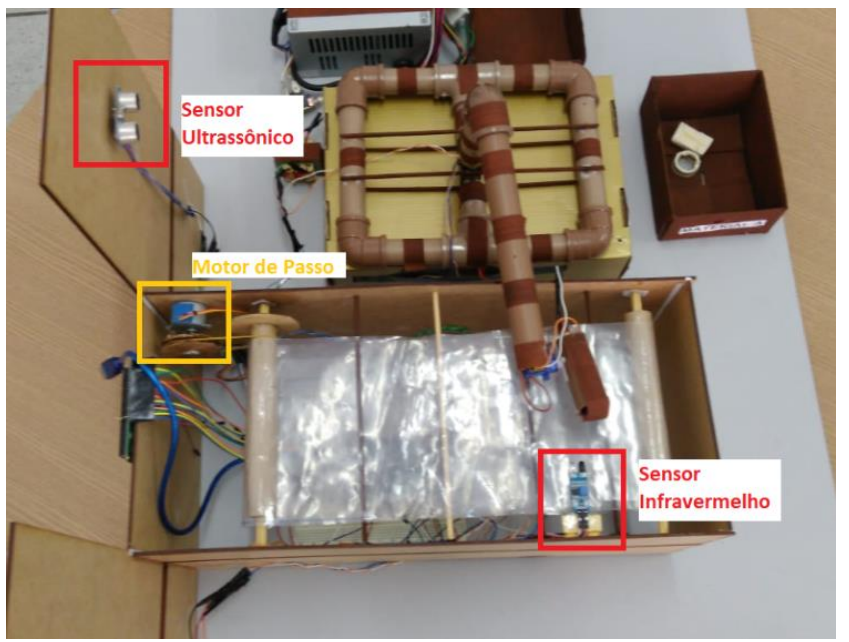

Fonte: Próprio Autor. 
A Figura 6 destaca outros elementos importantes do protótipo, como o eletroímã, transformador e fonte de alimentação de corrente contínua. Também é destacado os recipientes $(\mathrm{A}$ e $\mathrm{B})$, utilizados para seleção do material. O Arduino está localizado abaixo da correia transportadora da esteira, por isso não está visível nas Figura.

Figura 6. Localização de Fonte CC, Transformador, eletroímã e recipientes.

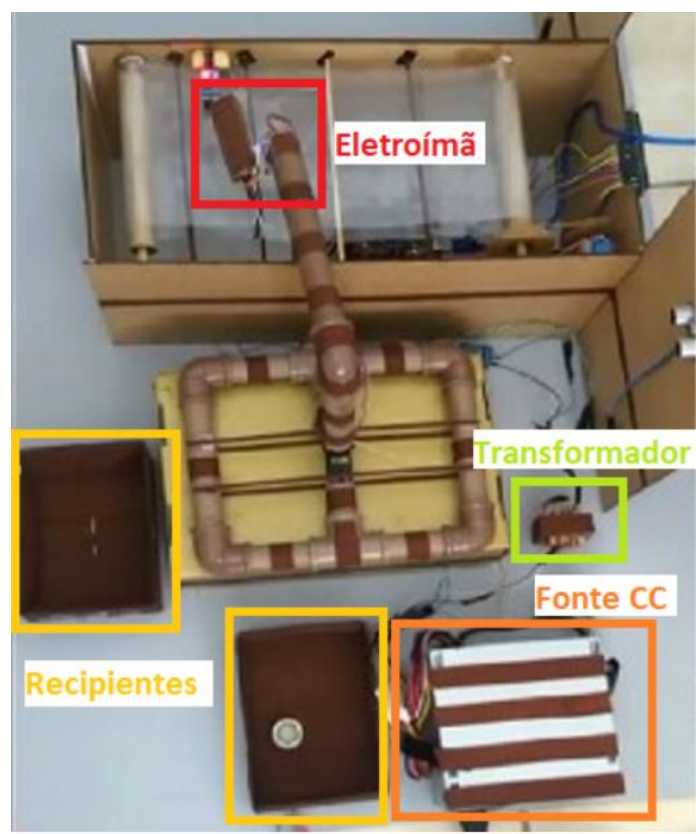

Fonte: Próprio Autor.

Por fim, A Figura 7 representa o guindaste, com destaque para os servo motores utilizados em sua confecção.

Figura 7. Localização de servo motores.

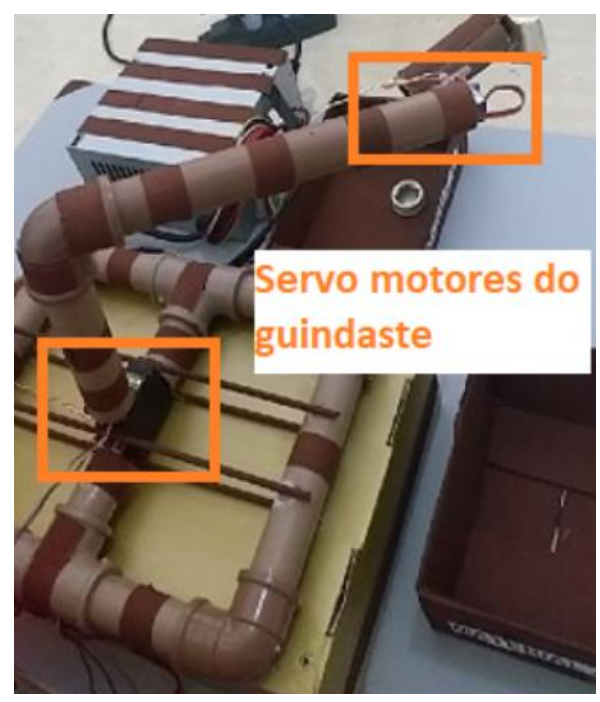

Fonte: Próprio Autor.

O projeto funcionou adequadamente, realizando todas as etapas e funções acordadas no escopo do projeto apresentado aos professores. No entanto, na etapa de 
montagem da parte física do protótipo houve a queima de um dos motores, exigindo alterações na estrutura física do projeto inicial para que o escopo acordado fosse cumprido, devido a não existência de um motor reserva e o curto prazo.

Observando-se o cronograma proposto para desenvolvimento do projeto, Tabela 1 percebe-se que as atividades de montagem da esteira e do braço, os testes e ajustes e a confecção do artigo, foram todas programadas para as últimas duas semanas do prazo. Este pequeno prazo para o cumprimento de diversas atividades foi um ponto negativo enfrentado para o desenvolvimento do projeto.

Além disso, foram encontrados outros erros de montagem, como por exemplo: erro no dimensionamento das polias utilizadas na relação entre eixo de motor de passo e eixo da esteira; a alimentação dos sensores ultrassônicos; e estabilidade da correia transportadora. Essas dificuldades foram de extrema importância para formação dos discentes, favorecendo a comunicação, criatividade e competência dos mesmos.

Diante destes acontecimentos, percebe-se que os discentes conseguiram propor soluções para os problemas em tempo hábil. Apesar disso, ficou evidente que a elaboração do cronograma não levou em consideração possíveis problemas de montagem e que as duas últimas semanas ficaram sobrecarregadas de tarefas, ficando como principal aprendizado no âmbito profissional, a importância e necessidade da utilização de um cronograma bem elaborado. Percebeu-se também, que cada integrante do grupo possui suas especificidades, facilidades e habilidades contribuindo assim, para a resolução dos contratempos ocorridos tanto na parte eletrônica, como também na de conversão.

\section{$5 \quad$ CONCLUSÕES}

Notou-se que o projeto interdisciplinar proposto contribuiu para a aprendizagem de conceitos envolvidos nas disciplinas de eletrônica e conversão, ambas do sexto período do curso de Engenharia Elétrica do IFMG Campus Formiga. Além do aprendizado específico de conteúdos como motores elétricos, eletroímãs, relés, sensores, atuadores, programação e Arduíno, o projeto permitiu a união desses conceitos, correlacionando as duas disciplinas do curso.O projeto também permitiu o desenvolvimento de habilidades de trabalho em equipe, atendimento aos prazos e capacidade de solucionar problemas. Tanto as habilidades específicas quantos as interpessoais são fundamentais para a formação dos profissionais em engenharia. $O$ projeto proposto foi apresentado e funcionou adequadamente, atendendo à todas as exigências estipuladas no escopo e no prazo determinado.

\section{REFERÊNCIAS}

Agnihotri, Nikhil. Stepper Motors or Step Motors. 2011. Disponível em: <https://goo.gl/eQcpWv>. Acesso em: 31 out. 2018.

Arduino. Disponivel em:http://arduino.cc/. Acesso em: 28 de Outubro de 2018.

Bertulucci Silveira, Cristiano. Sensor: Você Sabe o Que é Quais os Tipos?. 2016. Disponível em: <https://goo.gl/96u9mb>. Acesso em: 01 nov. 2018.

Bertulucci Silveira, Cristiano. Servo Motor: Veja como Funciona e Quais os Tipos . 2017. Disponível em: <https://goo.gl/rtRpTQ>. Acesso em: 31 out. 2018. 
Boylestad, Análise de Circuitos. Editora: Pearson - 10ª Edição, 2004.

Brites, Felipe; Santos, Vinícus. Motor de passo. Niterói, 2008.

Chapman - Electric Machinery Fundamentals - McGraw Hill.

Fonseca,E.G.P.;VEJA, A. S. Tutorial sobre introdução a projetos utilizando o kit de desenvolvimento Arduino. Anais: XXXIX Congresso Brasileiro de Educação em Engenharia, Cobenge. Blumenau:FURB,2011.

Franco Pinto, Leonardo. CONFIGURAC,AO E FUNCIONAMENTO DE UM SERVO ACIONAMENTO. 2014. 71 p. Trabalho de conclusão de curso (Graduação em Engenharia Elétrica) - UFRJ, Rio de Janeiro, 2014. Disponível em: <https://goo.gl/aAh3WK>. Acesso em: 31 out. 2018.

Masetto, M T. Aula na Universidade. Didática e Interdisciplinaridade. São Paulo: Editora Papirus, p. 179-192, 1998.

Motores de corrente contínua: Guia rápido para uma especificação precisa. 01. 2006. Disponível em: <https://goo.gl/gfc5LD>. Acesso em: 31 out. 2018.

Santos, Cristiano Aparecido; Santos, Eder Antonio Silva; Esteira Automatizada para Processos de Manufatura-Contribuições no Dessenvolvimento das Indústrias. Faculdade de Tecnologia de Garça - FATEC, 2014.

Silva, Marcio Gabriel.Avaliação de desempenho de relés de proteção digital.Rio de Janeiro.2012. 114 p., p.: il. Disponível em: https://goo.gl/q5RPtN

Silva, Jonathan. Como funciona um circuito rele com eletroímã . 2014. Disponível em: <https://goo.gl/yzShhL>. Acesso em: 31 out. 2018.

Thomsen, Adilson. Como conectar o Sensor Ultrassônico HC-SR04 ao Arduino . 2011. Disponível em: <https://goo.gl/gBhMg3>. Acesso em: 31 out. 2018.

Werner Puhlmamn, Henrique Frank. Módulo de Display LCD . 2015. Disponível em: <https://goo.gl/41xZMv>. Acesso em: 31 out. 2018.

Zaina, Luciana A. M., Caversan, Fabio L., Projeto Multidisciplinar: Uma Experiência Prática no ensino de Programação em um curso de Engenharia da Computação. Cobenge, Campina Grande - SP, Setembro, 2005.

\section{INSTRUCTIONS PROTOTYPE OF AN INDUSTRIAL SECTOR - DISTRIBUTION SECTOR}

Abstract: This document presents details of a project proposed by the disciplines of Conversion Laboratory and Electronics Laboratory II, which is a prototype of the industrial sector composed by a treadmill and a crane with an electromagnet. The crane must separate two materials led by the treadmill according to the command of an Arduino module. The means used to connect the whole system was the Arduino MEGA 2560, for which was 
developed an algorithm that worked as follows: By receiving a signal from one of two ultrasonic sensors, such signal is associated to the material to be transported and the data sent to an 16x2 LCD display; Thereafter, the stepper motor moving the treadmill is triggered and only interrupted when the infrared obstacle sensor detects that the transported material is found to be at the desired position. The servo at the top of the crane is then triggered, so is the electromagnet to attract the material along with the servo (the last of which would turn 90 if the first material is identified or 180 degrees if the second material is identified, deactivating the electromagnet). Finally, the base motor would get back at its starting position and the cycle would restart. Despite some unforeseen outcomes mainly related to the motors, the prototype was delivered and worked as expected

Keywords:Arduino.Electromagnet.Transporter Treadmill.Crane.Prototype. 